\title{
Choanal and cloacal aerobic bacterial flora in captive green iguanas: a comparative analysis
}

\author{
Silvia Barazorda Romero ${ }^{1}$, Alois Č́ížek ${ }^{2}$, Martina Masaříková ${ }^{2}$ Zdeněk Knotek $^{1}$ \\ University of Veterinary and Pharmaceutical Sciences Brno, Faculty of Veterinary Medicine, ${ }^{1}$ Avian and Exotic \\ Animal Clinic, ${ }^{2}$ Department of Infectious Diseases and Microbiology, Brno, Czech Republic
}

Received May 15, 2014

Accepted October 22, 2014

\begin{abstract}
The aims of this study were to characterize the choanal and cloacal aerobic bacterial flora in healthy captive green iguanas and to compare it with the bacterial flora of the biofilm present in the water container of each terrarium. Samples were collected from the choana and the cloaca of 20 healthy captive adult green iguanas and from the biofilm of 15 water containers. The final identification of aerobic bacteria was performed by matrix-assisted laser desorption ionization time-of-flight mass spectrometry. Salmonella positive samples were serotyped. The most common strains observed at each test location were from 1) choanae: Staphylococcus spp., Enterobacter cloacae and Comamonas testosteroni; 2) cloacae: Citrobacter spp., Salmonella spp. and Corynebacterium spp.; and 3) biofilms: Pseudomonas spp., Salmonella spp. and Acidovorax spp. We showed that apart from Salmonella spp., the choanal and cloacal bacterial flora differed from the microorganisms present in the biofilm of the animal's water container. These data revealed that healthy captive adult green iguanas harbored several aerobic bacterial strains that in immunosuppressed reptiles may act as opportunistic pathogens. Also, several of the aerobic bacteria identified in samples are potential zoonotic agents. Characterization of the normal background flora in captive reptiles and their environment can contribute to an understanding of the spread of bacterial contamination and the risk of potential zoonotic diseases for people in contact with these animals.
\end{abstract}

Reptiles, biofilm, matrix-assisted laser desorption ionization time-of-flight mass spectrometry, serotype

Previous studies in clinically healthy captive lizards showed a predominance of Pseudomonas spp., Aeromonas spp., Serratia spp. and Enterobacter spp. in the oral cavity of green iguanas (Barten 2002) and Citrobacter spp., Enterobacter spp., Escherichia coli, Klebsiella oxytoca, Salmonella spp., Pseudomonas aeruginosa, Corynebacterium spp., Staphylococcus spp., and Streptococcus spp. in the cloaca of giant lizards (Martínez Silvestre et al. 2003). These studies have helped us to understand the normal bacterial flora in captive lizards and to interpret the significance of bacterial strains in ill individuals.

Pet green iguanas are kept for many years in indoor terrariums. This situation leads us to consider the influence of the bacterial population in the biofilm that forms on the water container that is used by the lizard to drink from and bathe in, on the bacterial community of the lizard.

The aims of this study were to characterize and compare the aerobic bacterial flora between the choanal and cloacal sites in healthy captive adult green iguanas, and with the bacteria of the water container in their terrariums. This information will explore the hypothesis that the biofilm in water containers may perpetuate and spread bacterial contamination between animals and between terrariums. Furthermore, these data will contribute to knowledge of the normal background flora in pet iguanas and their environment, and for understanding the risk of potential zoonotic diseases for people in contact with these animals.

Address for correspondence:

MVDr. Silvia Barazorda Romero

Avian and Exotic Animal Clinic

Faculty of Veterinary Medicine

University of Veterinary and Pharmaceutical Sciences Brno

Palackého tř. 1/3, 61242 Brno, Czech Republic 


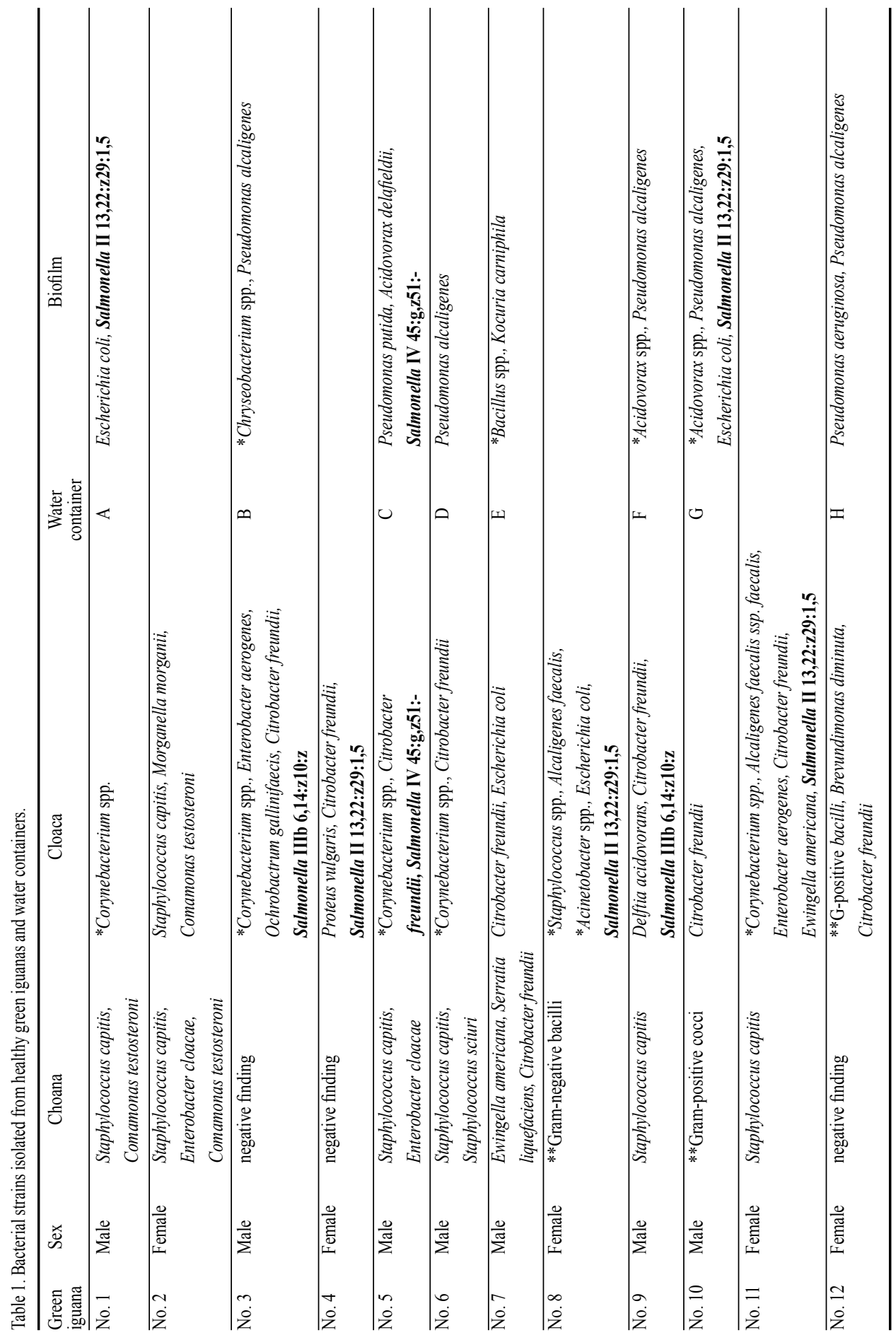




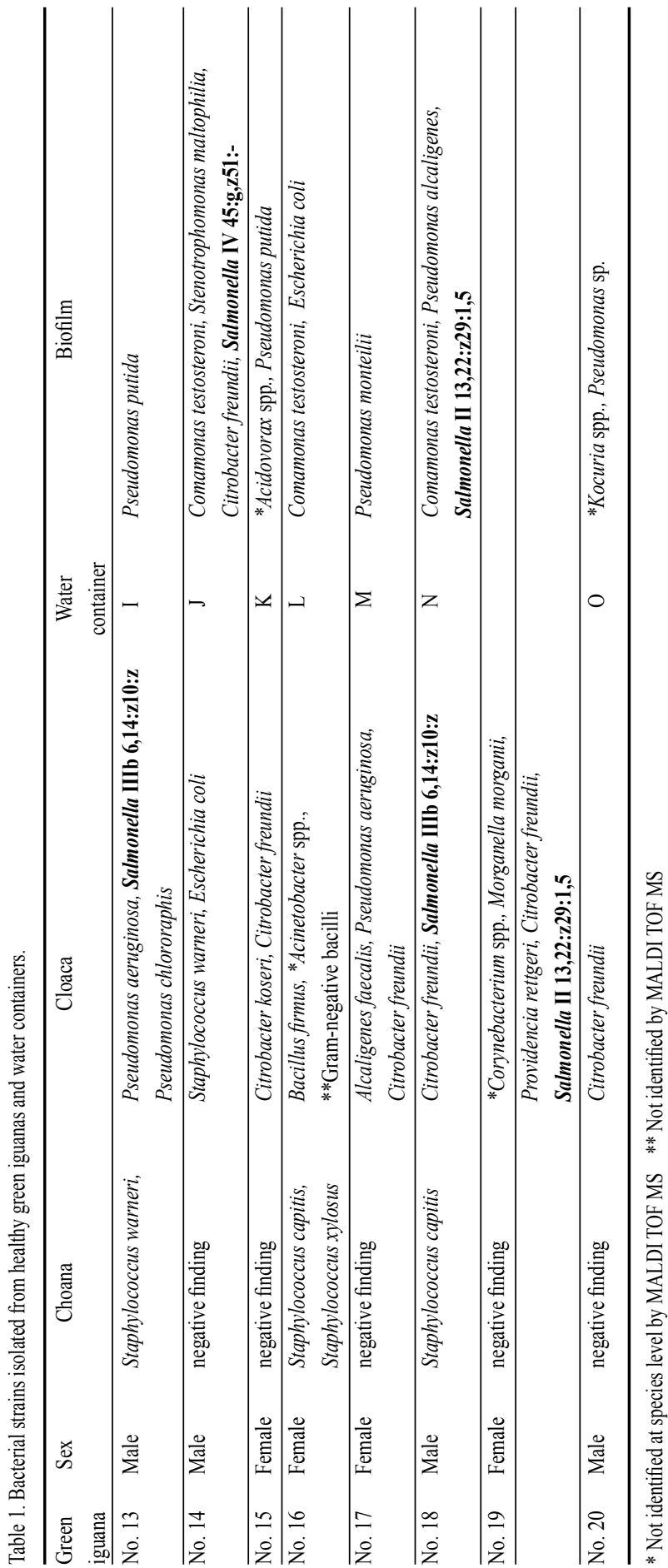

\section{Materials and Methods}

Animals and water containers

Twenty green iguanas (Iguana iguana), 11 males and 9 females, aged 10 to 14 years were included in this study. The green iguanas were acquired when young (6 months old) from the breeding program of the local zoo. They were kept in indoor terrariums for over 9 years on $12 \mathrm{~h}$ light regime, including UVB light source, at a temperature between 24 and $35^{\circ} \mathrm{C}$. The main food was fresh dandelion leaves, cabbage, carrots, cucumbers and apples. Newspaper was used as substrate which was exchanged at least $\times 3$ a week. Ten individuals (5 males and 5 females) were kept in pairs, and the other 10 were kept individually. Before sample collection, iguanas were clinically examined including haematology, plasma chemistry analyses, and parasitological examination of faecal samples. Within the period of the study, iguanas were healthy and sexually inactive. The animals were housed and handled in agreement with the Branch Commission for Animal Welfare of the Ministry of Education, Youth and Sports of the Czech Republic (accreditation No. 252013, MSMT-19018/2013-1, MSMT3XBZJE).

Each terrarium had a water container for drinking and bathing. The containers were cleaned every second day by scrubbing with a brush and rinsing with water. A thick and sticky layer known as biofilm was noted on the walls of the containers. A biofilm is a microbial community that is able to adhere to surfaces, it can resist removal by standard husbandry washing methods and it can survive for long periods in the environment.

\section{Sample collection}

Iguanas were manually restrained and sterile cotton swabs (Copan Italia S.p.A, Italy) were: a) gently rubbed along the choana, b) gently inserted and twirled into the cloaca. Water container samples were collected by wiping the biofilm using a 
sterile cotton swab. All samples were transported to bacteriological laboratory in Amies transport medium (Copan Italia S.p.A, Italy).

\section{Bacterial isolation and identification}

The samples were cultured on blood agar supplemented with 5\% sheep blood (Columbia Agar Base, Oxoid, Ltd., England) and MacConkey agar (Oxoid, Ltd., England). All samples were aerobically incubated at $25^{\circ} \mathrm{C}$ for 24-72 h. Cultures with mixed populations were subcultured on the same media. For Salmonella spp. detection, cloacal and biofilm samples were additionally incubated in buffered peptone water (Oxoid, Ltd., England) at $37^{\circ} \mathrm{C}$ overnight, then selectively enriched in modified semisolid Rappaport Vassiliadis medium (Oxoid, Ltd., England) at $41.5^{\circ} \mathrm{C}$ for 24 (48) h. Selected colonies were subcultured on xylose-lysine-deoxycholate agar (Oxoid, Ltd., England) and brilliant green agar (Oxoid, Ltd., England) at $37^{\circ} \mathrm{C}$ for $24 \mathrm{~h}$. The final identification of all isolated bacteria was performed by MALDI-TOF MS (MALDI Biotyper, Bruker Daltonics, Germany). Concordance studies show $99.1 \%$ and $99.4 \%$ agreement between MALDI TOF MS and conventional gold standard 16S rRNA gene sequencing (Cherkaoui et al. 2010).

Salmonella strains were serotyped by slide agglutination testing using two commercial O- and H- antisera (BioRad, France; Denka Seiken, Japan). Serotypes were designated according to the principles of the KauffmannWhite-Le Minor scheme (Grimont and Weill 2007).

\section{Results}

\section{Choana and cloaca}

Twenty one strains of aerobic bacteria were isolated from choanae (Table 1). The common strains were Staphylococcus spp. (S. capitis, S. xylosus, S. warneri, S. sciuri) (52.4\%), Comamonas testosteroni $(9.5 \%)$ and Enterobacter cloacae $(9.5 \%)$. Fifty seven strains of aerobic bacteria were obtained from cloacae. The common strains were Citrobacter spp. (C. freundii, C. koseri) (26.3\%), Salmonella spp. (15.8\%) and Corynebacterium spp. $(10.5 \%)$. Salmonella enterica was detected in 9 of 20 individuals and strains belonged to subspecies salamae (II), diarizonae (IIIb) and houtenae (IV). Each serotype was found in multiple individuals (Table 1). All 5 pairs of green iguanas had at least 1 aerobic bacterial species in common. However, no pairs shared the same Salmonella serotype.

\section{Biofilm in water containers}

Thirty three strains of aerobic bacteria were obtained from biofilms (Table 1). The common strains were Pseudomonas spp. (P. alcaligenes, P. putida, P. aeruginosa, P. monteilii) (36.4\%), Salmonella spp. (15.2\%) and Acidovorax spp. (A. delafieldii) $(12.1 \%)$. Salmonella enterica was detected in 5 of 15 water containers and the strains belonged to subspecies salamae (II) and houtenae (IV) (Table 1). Unexpectedly, the bacteria in the biofilms were not found in any of the choanae of the iguanas in the same terrarium. Apart from Salnonella spp., biofilms and cloacae also did not share the same bacteria, whereas 3 of the 20 iguanas had in their cloacae the same serotypes of Salmonella as the biofilm.

\section{Discussion}

The results of this investigation demonstrate that the aerobic bacterial flora in the choanae and cloacae of healthy captive green iguanas was composed of diverse microbial spectra. Those known to be capable of causing opportunistic infection in malnourished reptiles or kept at suboptimal environmental temperatures are: Acinetobacter spp., Stenotrophomonas maltophilia, Pseudomonas spp., Citrobacter spp., Proteus vulgaris, Enterobacter spp., Serratia spp., and Salmonella spp. (Mader 1998; Harris and Rogers 2001; Mehler and Bennett 2003). Thus, animals could be at risk if they develop concurrent illness or if husbandry standards deteriorate.

Of the bacteria considered to pose a potential health hazard to immunosuppressed and/or immunocompromised humans (Johnson-Delaney 2006), the following were identified in our cohort of healthy captive green iguanas: Stenotrophomonas maltophilia, Pseudomonas 
spp., Citrobacter spp., Enterobacter spp., Escherichia coli, Proteus spp., Serratia spp., and Salmonella spp. These species were present in our study with prevalence rates over $53.2 \%$ and are thus a potential zoonotic risk.

Salmonella species are known to be associated with ectotherms and also occur in their captive environment. It has been well documented that reptiles may spread Salmonella intermittently for a long time without showing any clinical signs of disease (Burnham et al. 1998; Mader 1998; Mitchell and Shane 2000). The narrow spectrum of Salmonella serotypes detected in the current study could be a consequence of the terrariums being isolated in the same room for many years. This could limit serotype exposure and allow cross contamination between individuals through husbandry. The Salmonella serotype II $13,22: \mathrm{z}_{29}: 1,5$ was found in 4 green iguanas in the current study, has previously been described in a pet turtle in Japan and free living tortoises in Morocco (Hidalgo-Vila et al. 2008; Lee et al. 2009). Serotype IIIb 6,14:z10:z was found in 4 green iguanas and has been reported in captive snakes in the United States (Goupil et al. 2012). The serotype IV $45: \mathrm{g}, \mathrm{z}_{51}:-$ was found in 1 green iguana, has been reported to be responsible for salmonellosis in humans after contact with a green iguana, bearded dragon and gecko (Woodward et al. 1997; Bertrand et al. 2008).

In this study, apart from the more widespread presence of Salmonella species, the choanal and cloacal aerobic bacterial flora differed from those present in biofilm of water containers. This may reflect the true distribution or be an artifact arising from the technique of biofilm sampling. Abrasive sponge swabbing of the highly adherent biofilm may release and so aid detection of more bacteria. Alternatively, choanal, cloacal, and biofilm environments likely provide different conditions that are optimal for different bacteria. The choanal and cloacal bacterial species showed some overlap with previous studies in other reptiles (Barten 2002; Martínez Silvestre et al. 2003); this may be due to species variation, exposure or housing and husbandry differences.

We have shown that the high throughput MALDI TOF MS technology can benefit studies of microorganisms in reptiles and the captive environment, allowing accurate identification at the species level of many Gram-positive and Gram-negative bacterial strains. Nevertheless, a user of this technology should be aware that it is limited to the detection of strains represented in the MALDI-TOF MS database at any one time and to those that can be cultured.

Animals in the current study were housed in the same room and cared for by the same staff. Investigation of the choana, cloaca, and biofilm in reptiles kept by the public in different households, and as a consequence under varied conditions, would better represent the zoonotic potential posed by reptile to owners in the community, and make an interesting comparison with the current isolated collection. Future studies will also be extended to identify anaerobic bacteria and fungi in captive green iguanas.

\section{Acknowledgements}

We thank Dr. Corinne Lendon BVsc, BSc, PGCert L\&T, PhD for her valuable suggestions, critical comments and correction of English, Doc. MVDr. Renata Karpíšková, PhD and Mgr. Petra Myšková at the Veterinary Research Institute, Brno, Czech Republic for determination of Salmonella serotypes and technicians at the Avian and Exotic Animal Clinic for the professional care of green iguanas. The project received partial funding from the Faculty of Veterinary Medicine (Institucionalni vyzkum FVL-2013).

\section{References}

Barten SL 2002: Diseases of the iguana oral cavity. Bayer Exotics Symposium, selected papers on the green iguana and antimicrobials in exotic pets, Supplement to Comp Cont Educ Pract 24: 38-42

Bertrand S, Rimhanen-Finne R, Weill FX, Rabsch W, Thornton L, Perevoscikovs J, van Pelt W, Heck M 2008 : Salmonella infections associated with reptiles: the current situation in Europe. Euro Surveill 13: pii=18902

Burnham BR, Atchley DH, DeFusco RP, Ferris KE, Zicarelli JC, Lee JH, Angulo FJ 1998: Prevalence of fecal 
shedding of Salmonella organisms among captive green iguanas and potential public health implications. J Am Vet Med Assoc 213: 48-50

Cherkaoui A, Hibbs J, Emonet S, Tangomo M, Girard M, Francois P, Schrenze J 2010: Comparison of two Matrixassisted laser desorption ionization-time of flight mass spectrometry methods with conventional phenotypic identification for routine identification of bacteria to the species level. J Clin Microbiol 48: 1169-1175

Grimont PAD, Weill FX 2007: Antigenic formulae of the Salmonella serovars. WHO Collaborating Centre for Reference and Research on Salmonella, Institut Pasteur, Paris $166 \mathrm{p}$.

Goupil BA, Trent AM, Bender J, Olsen KE, Morningstar BR, Wünschmann A 2012: A longitudinal study of Salmonella from snakes used in a public outreach program. J Zoo Wildl Med 43: 836-841

Harris NB, Rogers DG 2001: Septicemia associated with Stenotrophomonas maltophilia in a West African dwarf crocodile (Osteolaemus tetraspis subsp. tetraspis). J Vet Diagn Invest 13: 255-258

Hidalgo-Vila J, Díaz-Paniagua C, Ruiz X, Portheault A, El Mouden H, Slimani T, de Frutos C, de Caso MS 2008 : Salmonella species in free-living spur-thighed tortoises (Testudo graeca) in central western Morocco. Vet Rec 162: $218-219$

Johnson-Delaney CA 2006: Reptile zoonoses and threats to public health. In: Mader DR (2 ${ }^{\text {nd }}$ Ed.): Reptile Medicine and Surgery. Saunders-Elsevier Publishing, St. Louis, pp. 1017-1030

Lee K, Iwata T, Shimizu M, Taniguchi T, Nakadai A, Hirota Y, Hayashidani H 2009: A novel multiplex PCR assay for Salmonella subspecies identification. J Appl Microbiol 107: 805-811

Mader DR 1998: Common bacterial disease and antibiotic therapy in reptiles. Antimicrobial Therapy in Exotics, Supplement to Comp Cont Educ Pract 20: 23-33

Martínez Silvestre A, Silveira L, Mateo JA, Urioste J, Rodríguez Domínguez MA, Pether J 2003: Cloacal microbiology in threatened captive giant lizards from the Canary Islands (genus Gallotia). Rev Esp Herp 17: 29-37

Mehler SJ, Bennett RA 2003: Oral, dental, and beak disorders of reptiles. Vet Clin Exot Anim 6: 477-503

Mitchell MA, Shane SM 2000: Preliminary findings of Salmonella spp. in captive green iguanas (Iguana iguana) and their environment. Prev Vet Med 45: 297-304

Woodward DL, Khakhria R, Johnson WM 1997: Human salmonellosis associated with exotic pets. J Clin Microbiol 35: 2786-2790 